\title{
Atividade antimicrobiana in vitro de extrato etanólico de própolis da abelha Scaptotrigona aff. Postica (Latreille, 1807)
}

\begin{abstract}
As abelhas nativas são importantes animais para diversas áreas de estudo, não só pelas peculiaridades do mel produzido, mas por seus exemplos de organização ecológica e por todos os demais produtos e subprodutos dessas atividades, com destaque para a produção de própolis e geoprópolis, amplamente trabalhados na meliponicultura, uma área da zootecnia que se dedica a estudar as abelhas sem ferrão (chamadas de meliponinas), como as nativas do Brasil. O objetivo desse trabalho foi avaliar o potencial antibacteriano do extrato etanólico da própolis (EEP) da abelha nativa Scaptotrigona affinis postica frente as bactérias Listeria monocytogenes, Staphylococcus aureus, Streptococcus mutans e Escherichia coli, considerando esta como uma possibilidade de uso de um recurso natural eficaz no controle das bactérias listadas, bem como dos malefícios associados a ocorrência delas. As amostras de própolis foram coletadas em meliponário localizado na cidade de Barra do Corda/MA, sendo dissolvido $100 \mathrm{~g}$ de amostra coletada em $1000 \mathrm{~mL}$ de álcool 70\% para a obtenção do seu extrato etanólico, com posterior evaporação do solvente. A possível ação inibitória do EEP foi avaliada por meio da técnica de Disco Difusão em ágar, sendo utilizado como padrão antibacteriano o antibiótico Ciprofloxacino (a $60 \mu \mathrm{g} / \mathrm{mL}$ ), com testagem do extrato etanólico da própolis nas concentrações de $0,25 \mathrm{mg} / \mathrm{mL}, 0,5 \mathrm{mg} / \mathrm{mL}, 1 \mathrm{mg} / \mathrm{mL}$ e $2 \mathrm{mg} / \mathrm{mL}$. Dentre as seis ATCC's bacterianas testadas o Ciprofloxacino se mostrou mais eficiente frente a Escherichia coli (ATCC 25922). As amostras de extrato etanólico da própolis da abelha Scaptotrigona affinis postica, em todas as concentrações testadas, não apresentaram atividade antimicrobiana contra os microrganismos testados, requerendo mais estudos e caracterizações.
\end{abstract}

\section{In vitro antimicrobial activity of ethanol extract of bee propolis Scaptotrigona aff. Postica (Latreille, 1807)}

\begin{abstract}
Native bees are important animals for different areas of study, not only for the peculiarities of their production, but for their examples of ecological organization and for all the other products and byproducts of these activities, with emphasis on the production of propolis and geopropolis, specially worked in meliponiculture, an area of zootechnics dedicated to studying how stingless bees (called meliponins), as well as those native to Brazil. The goal of this work was to evaluate the antibacterial potential of the ethanol extract of propolis (EEP) of native bee Scaptotrigona affinis postica against the bacteria Listeria monocytogenes, Staphylococcus aureus, Streptococcus mutans and Escherichia coli, considering this as a possibility of using an effective natural resource in the control of the discriminated bacteria, as well as the harm associated with their occurrence. The propolis samples were collected in a meliponary located in the city of Barra do Corda/MA, being dissolved $100 \mathrm{~g}$ of sample collected in $1000 \mathrm{~mL}$ of $70 \%$ alcohol to obtain its ethanolic extract, with subsequent evaporation of the solvent. The possible inhibitory action of EEP was evaluated using the Disc Diffusion Agar technique, using the antibiotic Ciprofloxacin (at $60 \mu \mathrm{g} / \mathrm{mL}$ ) as an antibacterial standard, with testing the propolis ethanolic extract at concentrations of $0.25 \mathrm{mg} / \mathrm{mL}, 0.5 \mathrm{mg} / \mathrm{ml}, 1 \mathrm{mg} / \mathrm{ml} \mathrm{and} 2 \mathrm{mg} / \mathrm{ml}$. Among the six bacterial ATCC's tested, Ciprofloxacino proved to be more efficient compared to Escherichia coli (ATCC 25922). Samples of ethanolic extract of bee propolis Scaptotrigona affinis postica, in all concentrations tested, did not show antimicrobial activity against the tested microorganisms, requiring further studies and characterization.
\end{abstract}

Keywords: Antimicrobian activity; Native bees; Toxicity; Diffusion Disc.

Topic: Uso de Recursos Naturais

Reviewed anonymously in the process of blind peer.

Nilson dos Santos Loiola

Universidade do Vale do Taquari, Brasil

http://lattes.cnpq.br/4277571699501201

http://orcid.org/0000-0002-4641-5864

nilson.loiola@universo.univates.br

Eduardo Miranda Ethur (iD

Universidade do Vale do Taquari, Brasil

http://lattes.cnpq.br/0536800052883688

http://orcid.org/0000-0003-1731-3778

eduardome@univates.br

Ani Caroline Weber

Universidade do Vale do Taquari, Brasil

http://lattes.cnpq.br/8238624023188773

http://orcid.org/0000-0002-5009-7280

ani.weber@universo.univates.br

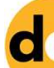

DOI: 10.6008/CBPC2179-6858.2020.006.0049
Received: 05/10/2020

Approved: 26/11/2020

\section{Referencing this:}

LOIOLA, N. S.; ETHUR, E. M.; WEBER, A. C.. Atividade antimicrobiana in vitro de extrato etanólico de própolis da abelha Scaptotrigona aff. Postica (Latreille, 1807). Revista Ibero Americana de Ciências Ambientais, v.11, n.6, p.612-620, 2020. DOI: http://doi.org/10.6008/CBPC2179-6858.2020.006.0049 


\section{INTRODUÇÃO}

Estudos sobre as abelhas bem como dos produtos inerentes ao nicho ecológico desses insetos são de extrema importância para o entendimento do meio natural e da conservação da biodiversidade local, não só pelos benefícios agregados ao mel, mas também pelo serviço ambiental prestado através da polinização, manutenção dos ecossistemas naturais, agrícolas e na produção de alimentos que, segundo estimativas, um terço da alimentação humana é resultado direto e/ou indireto da polinização realizada pelas abelhas (VILLASBÔAS, 2018).

As abelhas encontram-se reunidas dentro da superfamília Apoidea que integra as famílias Adrenidae, Colletidae, Dasypodaidae, Halictidae, Megachilidae, Meganomiidae, Melittidae, Stenotritidae e Apidae, compreendendo cerca de 20.000 espécies de abelhas pelo mundo, boa parte dessas estando presentes no Brasil, como é o caso da abelha Tubi, Scaptotrigona aff. Postica (LATREILLE, 1807), objeto deste trabalho (PIANARO, 2012).

Um produto natural oriundo da meliponicultura (criação de abelhas nativas) e muito pesquisado nos últimos anos tem sido a própolis que, apesar das várias pesquisas já realizadas, ainda desperta trabalhos haja visto a sua complexa constituição, sendo resultante das atividades das abelhas a partir da mistura de substâncias coletadas de diferentes partes das plantas (brotos, botões florais e exsudatos resinosos), de diversas origens vegetais, somadas à secreções produzidas pelo organismo da própria abelha, somados a cera, pólen e podendo conter ainda minerais como barro (COSTA et al., 2014).

Desde o início da humanidade está vem aprendendo a aplicar os recursos naturais em benefício da saúde e dentre esses recursos está o uso da própolis, cujos primeiros registros de emprego na medicina há, pelo menos, 300 a.C., foram descritos pelos assírios, gregos, romanos, incas e egípcios, se estendendo até a contemporaneidade (LUSTOSA, 2007).

O uso da própolis é antigo, principalmente na medicina tradicional, sendo hoje um produto apícola de largo uso em todo o mundo com uma vasta lista de relatos sobre as atividades biológicas da própolis, dentre elas atividades anticâncer, antioxidante, anti-inflamatório, antibiótico e antifúngico (GHISALBERTI, 1979; BURDOK, 1998; MARCUCCI, 1995).

Cerca de 300 compostos, relacionados a diversos benefícios, já foram identificados em diferentes amostras de própolis, incluindo: ésteres de ácidos fenólicos, diversos flavonoides, terpenos, $\beta$-esteroides, álcoois e aldeídos aromáticos, sesquiterpenos, naftalenos, dentre outros (LUSTOSA, 2007).

A necessidade de novos produtos, associados a técnicas sustentáveis de manejo e que apresentem propriedades bioativas, aliados ao grande avanço da fitoterapia nos últimos anos, tem estimulado estudos sobre a ação antimicrobiana de diferentes substâncias que possuam propriedades terapêuticas importantes para diversos ramos da indústria e da saúde.

Dentre os grupos microbianos as bactérias Listeria monocytogenes, Staphylococcus aureus, Streptococcus mutans e Escherichia coli possuem um expressivo potencial infeccioso, podendo estar associadas a casos de mortalidade, além de possuírem relevantes mecanismos evolutivos de resistência e 
proliferação, mesmo quando submetidas a variadas condições, o que levanta grande preocupação para a Saúde Pública, pois requerem ações de vigilância constante e chamam a atenção para estudos gerais nas áreas da Microbiologia, bem como na Indústria de Alimentos.

Nesse sentido, o presente trabalho analisou amostras de própolis de meliponário de área ribeirinha ao Rio Mearim, na cidade de Barra do Corda - MA, centro sul maranhense, objetivando avaliar o potencial antimicrobiano da própolis da abelha nativa Scaptotrigona aff. Postica (LATREILLE, 1807) frente a bactérias gram-positivas (Listeria monocytogenes, Staphylococcus aureus e Streptococcus mutans) e da bactéria gramnegativa (Escherichia coli) comparando sua ação com a de agentes antimicrobianos de primeira escolha da medicina.

Existe, por tanto, um interesse cada vez maior da indústria em conhecer os mecanismos de ação de produtos de origem natural como a própolis, com destaque para a indústria farmacêutica, muito estimulada pela busca de métodos mais naturais de promover a saúde humana, sem efeitos colaterais adversos, como no combate a agentes microbianos a exemplo da Listeria monocytogenes, Staphylococcus aureus, Streptococcus mutans e Escherichia coli e tais indicativos de possíveis aplicações da própolis, mediante seus princípios bioativos, provocou e justificou a execução deste trabalho de pesquisa.

\section{MATERIAIS E MÉTODOS}

A metodologia deste trabalho consistiu em um estudo experimental, in vitro, controlado, realizado no laboratório de Química e Microbiologia da Universidade do Vale do Taquari (UNIVATES)/Lajeado - Rio Grande do Sul, Brasil.

\section{Área de estudo}

A própolis foi coletada em meliponário localizado na cidade de Barra do Corda - MA (S 5³0’37", W $45^{\circ} 15^{\prime} 42^{\prime \prime}$ ), utilizada para obtenção de extrato etanólico em laboratório, sendo então submetido a testes de sensibilidade antimicrobiana através do estudo de halos de inibição por difusão em disco, como segue:

\section{Procedimentos experimentais}

\section{Obtenção do Extrato Etanólico de Própolis (EEP)}

O extrato etanólico de própolis foi obtido a partir de 100 g de própolis dissolvida em $1000 \mathrm{~mL}$ de etanol a 70\%, com solvente posteriormente evaporado e obtendo-se o extrato seco. O EEP ficou guardado sob refrigeração até os momentos dos ensaios fitoquímicos.

Para obtenção da diluição do extrato etanólico foi pesado 0,2 g do EEP, acrescentando parcelas de álcool de cereais e realizada agitação constante com o auxílio de uma espátula metálica. Cada porção diluída foi então transferida para um balão volumétrico de $10 \mathrm{~mL}$, até obter-se a diluição total do valor pesado e atingir-se a marca de $10 \mathrm{~mL}$ do volume do balão. Ao final se obteve um diluído de $20 \mathrm{mg} / \mathrm{mL}$ a partir do extrato de própolis. 
Para análise de diferentes concentrações do extrato foi realizada a diluição seriada do mesmo, obtendo-se concentrações de $0,25 \mathrm{mg} / \mathrm{mL}, 0,5 \mathrm{mg} / \mathrm{mL}, 1 \mathrm{mg} / \mathrm{mL}$ e $2 \mathrm{mg} / \mathrm{mL}$.

\section{O meio de cultura}

Foi utilizado como meio de cultura para os grupos microbianos o ágar Müeller-Hinton, utilizando-se água destilada como solvente. A seguir, o meio preparado foi esterilizado e, após resfriamento prévio dentro do fluxo laminar, este foi transferido para 60 placas de Petri $(90 \times 15 \mathrm{~mm})$ esterilizadas.

Cada placa recebeu $20 \mathrm{~mL}$ do meio ágar $\mathrm{MH}$, ficando com uma espessura de $3 \mathrm{~mm}$. Foram preparadas mais placas que o necessário de modo a escolher as mais uniformes após o resfriamento total do meio de cultura, processo ocorrido dentro da capela de fluxo laminar, à temperatura ambiente.

As placas com o meio foram então transferidas para estufa bacteriológica e, no dia seguinte, caso não tenha sido evidenciado contaminação, as mesmas foram utilizadas para a inoculação dos microorganismos testados.

\section{Micro-organismos utilizados}

As cepas bacterianas de referência utilizadas para avaliação da atividade antimicrobiana e da Concentração Inibitória Mínima (CIM) foram linhagens padrão American Type Culture Collection (ATCC) de: Listeria monocytogenes (7644, 13932 e 19114), Staphylococcus aureus (25923), Streptococcus mutans (25175) e Escherichia coli (25922). Estas foram ajustadas com salina 0,85\% (solução salina 0,85 a 0,9\%) correspondendo à concentração de $1 \times 10^{8}$ UFC, ou seja, a 0,5 na escala de McFarland (CLSI, 2015).

\section{Inoculação do meio}

Cada suspensão microbiana (ATCC) padronizada foi semeada em oito placas de ágar MH, utilizando alíquotas de $100 \mu \mathrm{L}$, totalizando 48 placas semeadas a serem testadas. A semeadura foi realizada espalhando uniformemente por todo a superfície do ágar os $100 \mu \mathrm{L}$ do inóculo com o auxílio de uma alça de inoculação.

\section{Disco Difusão em ágar}

O teste foi realizado em triplicata dispondo na superfície de cada placa, previamente inoculada, três discos de papel filtro de aproximadamente $7 \mathrm{~mm}$ de diâmetro, de forma equidistantes, previamente confeccionados e esterilizados, contendo o mesmo componente a ser testado e na mesma concentração (10 $\mu \mathrm{L})$.

Para a Listeria monocytogenes optou-se por pipetar a solução sobre os discos dispostos em placa de Petri aberta, a fim de promover a evaporação do álcool, em seguida foram mantidos em estufa, para secagem final da solução, só então foram dispostos sobre a placa de Petri semeada com o inóculo. Para a Staphylococcus aureus, Streptococcus mutans e Escherichia coli optou-se por pipetar a solução a ser testada diretamente sobre os discos já dispostos na placa semeada com o inóculo.

Após aplicação dos discos, as placas foram dispostas na estufa bacteriológica na posição invertida, 
assegurando que os discos não caíssem da superfície do ágar. Foram utilizados como grupos controle: solução de Ciprofloxacino a $60 \mu \mathrm{g} / \mathrm{mL}$, álcool de cereais puro, álcool 70\%, água destilada e EEP nas concentrações de $0,25 \mathrm{mg} / \mathrm{mL}, 0,5 \mathrm{mg} / \mathrm{mL}, 1 \mathrm{mg} / \mathrm{mL}$ e $2 \mathrm{mg} / \mathrm{mL}$.

\section{Incubação e Determinação da Concentração Inibitória Mínima (CIM)}

As placas foram então incubadas a $35 \pm 1^{\circ} \mathrm{C}$ por 24 horas. Após incubação, com o auxílio de uma régua milimetrada e uma boa fonte de luz refletida, a atividade antimicrobiana foi mensurada através da medida do diâmetro $(\mathrm{mm})$ da zona de inibição (halo) formada ao redor de cada disco (FERRONATTO et al., 2007).

Foi considerado como Concentração Inibitória Mínima do grupo experimental Extrato Etanólico de Própolis a menor concentração empregada em disco que tenha promovido a formação de halo de inibição.

\section{Interpretação dos resultados}

Foram realizadas as médias e desvios padrão das triplicatas das medidas dos halos de inibição frente aos grupos experimentais. Os resultados foram analisados pelo teste de Tukey com nível de significância de 5\%. Os dados foram analisados e processados com o auxílio do programa Excel e BioEstat versão 5.3.

\section{RESULTADOS}

Os resultados desse trabalho demonstram haver diferença estatística significante entre o controle positivo (Ciprofloxacino a $60 \mu \mathrm{g} / \mathrm{mL}$ ) e os demais grupos experimentais testados, conforme tabelas a seguir.

Tabela 1: Média e desvio padrão dos halos de inibição bacteriana dos grupos experimentais em mm frente a Listeria monocytogenes $(\mathrm{N}=3)$.

\begin{tabular}{|c|c|c|c|c|c|c|}
\hline \multirow{2}{*}{ Grupo experimental } & \multicolumn{2}{|c|}{ ATCC 19114} & \multicolumn{2}{|c|}{ ATCC 7644} & \multicolumn{2}{|c|}{ ATCC 13932} \\
\hline & Média & Desvio Padrão & Média & Desvio Padrão & Média & Desvio Padrão \\
\hline Ciprofloxacino & 14.333 & 0.471 & 10 & 0 & 10 & 0 \\
\hline Álcool de cereais puro & 0 & 0 & 0 & 0 & 0 & 0 \\
\hline Água & 0 & 0 & 0 & 0 & 0 & 0 \\
\hline Álcool 70\% & 0 & 0 & 0 & 0 & 0 & 0 \\
\hline $0.25 \mathrm{mg} / \mathrm{mL}$ & 0 & 0 & 0 & 0 & 0 & 0 \\
\hline $0.5 \mathrm{mg} / \mathrm{mL}$ & 0 & 0 & 0 & 0 & 0 & 0 \\
\hline $1 \mathrm{mg} / \mathrm{mL}$ & 0 & 0 & 0 & 0 & 0 & 0 \\
\hline $2 \mathrm{mg} / \mathrm{mL}$ & 0 & 0 & 0 & 0 & 0 & 0 \\
\hline
\end{tabular}

Legenda: $\mathrm{N}$ - número de repetições.

Tabela 2: Média e desvio padrão dos halos de inibição bacteriana dos grupos experimentais em $\mathrm{mm}$ frente a Staphylococcus aureus ( $\mathrm{N}=3$ ).

\begin{tabular}{l|l|l}
\hline \multirow{2}{*}{ Grupo experimental } & ATCC 25923 & Desvio Padrão \\
\cline { 2 - 3 } & Média & 0.471 \\
\hline Ciprofloxacino & 15.666 & 0.471 \\
\hline Álcool de cereais puro & 7.666 & 0 \\
\hline Água & 0 & 0 \\
\hline Álcool $70 \%$ & 0 & 0 \\
\hline $0.25 \mathrm{mg} / \mathrm{mL}$ & 0 & 0 \\
\hline $0.5 \mathrm{mg} / \mathrm{mL}$ & 0 & 0 \\
\hline $1 \mathrm{mg} / \mathrm{mL}$ & 0 & 0 \\
\hline $2 \mathrm{mg} / \mathrm{mL}$ & 0 &
\end{tabular}

\footnotetext{
Legenda: $\mathrm{N}$ - número de repetições.
} 
Tabela 3: Média e desvio padrão dos halos de inibição bacteriana dos grupos experimentais em $\mathrm{mm}$ frente a Straptococcus mutans $(\mathrm{N}=3)$.

\begin{tabular}{l|l|l}
\hline \multirow{2}{*}{ Grupo experimental } & ATCC 25175 & Desvio Padrão \\
\cline { 2 - 3 } & Média & 0.471 \\
\hline Ciprofloxacino & 7.333 & 0 \\
\hline Álcool de cereais puro & 0 & 0 \\
\hline Água & 0 & 0 \\
\hline Álcool $70 \%$ & 0 & 0 \\
\hline $0.25 \mathrm{mg} / \mathrm{mL}$ & 0 & 0 \\
\hline $0.5 \mathrm{mg} / \mathrm{mL}$ & 0 & 0 \\
\hline $1 \mathrm{mg} / \mathrm{mL}$ & 0 & 0 \\
\hline $2 \mathrm{mg} / \mathrm{mL}$ & 0 & \\
\hline
\end{tabular}

Legenda: $\mathrm{N}$ - número de repetições.

Tabela 4: Média e desvio padrão dos halos de inibição bacteriana dos grupos experimentais em mm frente a Escherichia coli $(\mathrm{N}=3)$

\begin{tabular}{l|l|l}
\hline \multirow{2}{*}{ Grupo experimental } & \multicolumn{2}{l}{ ATCC 25922 } \\
\cline { 2 - 3 } & Média & Desvio Padrão \\
\hline Ciprofloxacino & 23,666 & 0.613 \\
\hline Álcool de cereais puro & 0 & 0 \\
\hline Água & 0 & 0 \\
\hline Álcool $70 \%$ & 0 & 0 \\
\hline $0.25 \mathrm{mg} / \mathrm{mL}$ & 0 & 0 \\
\hline $0.5 \mathrm{mg} / \mathrm{mL}$ & 0 & 0 \\
\hline $1 \mathrm{mg} / \mathrm{mL}$ & 0 & 0 \\
\hline $2 \mathrm{mg} / \mathrm{mL}$ & 0 & 0 \\
\hline
\end{tabular}

Legenda: $\mathrm{N}$ - número de repetições.

Evidenciou-se a formação de halos de inibição apenas no antibiótico ciprofloxacino a $60 \mu \mathrm{g} / \mathrm{mL}$, em reação a todas as cepas testadas, e halos de inibição na reação entre o álcool de cereais puro e a cepa de Staphylococcus aureus. Em todas as amostras observou-se uma diferença estatística significante entre o ciprofloxacino e demais grupos experimentais, registrando $p<0,05$.

\section{DISCUSSÃO}

Todas as cepas bacterianas testadas foram sensíveis ao antibiótico comercial Ciprofloxacino (usado como padrão antimicrobiano) e as médias dos halos de inibição formados pela ação desse antibiótico mostram que o mesmo é mais eficiente frente à bactéria Escherichia coli (ATCC 25922) do que contra a $S$. aureus (ATCC 25923), seguido de uma menor ação contra as bactérias L. monocytogenes (ATCC's 19114, 7644 e 13932) e com uma ação mais inferior frente a S. mutans (ATCC 25175), demonstrando aqui uma maior indicação contra os distúrbios intestinais promovidos pela E. coli e menos indicado frente à cárie dentária desencadeada pela ação da S. mutans.

Além do padrão antimicrobiano também foi evidenciado que o álcool de cereais, dentre o grupo experimental, foi o único a demonstrar alguma ação antibacteriana, sendo está apenas frente a bactéria $S$. aureus, sem efeitos sobre as demais cepas testadas. Ainda assim, a ação antibacteriana do álcool de cereais foi bem inferior ao efeito demonstrado pelo padrão antimicrobiano testado.

Em estudo semelhante Trindade (2012) verificou que a própolis da abelha Scaptotrigona depilis se mostrou eficaz frente ao fungo Candida albicans, à bactéria gram-positiva Staphylococcus aureus e não exerceu nenhum efeito sobre a bactéria gram-negativa Escherichia coli, sendo que, apenas a falta de 
atividade frente a Escherichia coli coincidiu com este estudo.

Estudos com compostos do grupo dos flavonoides de amostras de própolis têm mostrado boa ação contra atividade bacteriana, em especial contra as gram-positivas, tendo uma ação mais limitada contra as gram-negativas, o que pode estar associado à complexidade da parede celular dessas bactérias bem como à presença de seus componentes lipídicos que formam uma barreira à ação dos compostos bioativos da própolis (PINTO et al., 2011).

Marcucci (1996) já havia relatado que a própolis, tanto isolada como em associação, possui propriedades biológicas, tais como: ação antimicrobiana frente a bactérias gram-positivas e gram-negativas.

Bankova et al. (1996) analisaram halos de inibição formados pela própolis brasileira e pelos seus constituintes em reação contra Staphylococcus aureus e estudos com S. aureus também foram realizados por Miorin et al. (2003), onde demonstraram que a própolis brasileira da abelha Tetragonisca angustula, quando comparada com a própolis da abelha Apis mellifera possui alta atividade contra S. aureus, superando também o efeito promovido pelo mel de ambas as abelhas testadas.

Tais estudos alertam para a necessidade de caracterizar e analisar os potenciais de ação dos produtos derivados das diversas abelhas nativas do Brasil, já o presente trabalho, por sua vez, não evidenciou ação antimicrobiana frente às cepas testadas de nenhum dos dois grupos bacterianos. Entretanto, a relação entre a estrutura química e a atividade antibacteriana dos constituintes da própolis é dado que ainda levanta questionamentos a serem explicados (GHISALBERTI, 1979; BURDOCK, 1998).

Vale ressaltar que a técnica de difusão em ágar é uma das mais consolidadas quando se pretende avaliar a ação antibacteriana de uma determinada substância frente a um grupo amostral. No entanto, essa técnica possui condições que se tornam fatores limitantes durante sua aplicação, como as diferenças de solubilidade e difusão no meio, dependendo da substância que está sendo avaliada, a presença de enzimas bacterianas, o tempo utilizado na incubação, a temperatura empregada, dentre outras (ESTRELA et al., 2001).

É preciso considerar também que a não formação de halos de inibição nem sempre significa exatamente que uma substância testada seja ineficiente quanto seu possível potencial antibacteriano e isso pode estar relacionado a dificuldades de difusão no meio. A dificuldade de difusão pode ocorrer devido haver nos meios de cultura substâncias tamponadoras, o que pode fazer com que a difusão ocorra de forma lenta em razão da baixa solubilidade da substância. É ainda importante considerar que a técnica de difusão em ágar é mais eficiente para teste com substâncias solúveis em água e a própolis é uma substância não solúvel em água (GOMES et al., 2006).

\section{CONCLUSÕES}

Os resultados da presente pesquisa para o Teste de Sensibilidade Antimicrobiana (TSA) por Disco Difusão em ágar indicam que os extratos etanólicos de própolis da abelha Scaptotrigona aff. Postica se mostraram ineficientes nas concentrações de $0,25 \mathrm{mg} / \mathrm{mL}, 0,5 \mathrm{mg} / \mathrm{mL}, 1 \mathrm{mg} / \mathrm{mL}$ e $2 \mathrm{mg} / \mathrm{mL}$ em estudos in vitro frente as cepas bacterianas de Listeria monocytogenes, Staphylococcus aureus, Streptococcus mutans e Escherichia coli analisadas. 
Mesmo a própolis da abelha Scaptotrigona affinis postica já ter sido alvo de estudos exitosos quanto o seu efeito frente a formas de câncer, como em estudos sobre o combate a tumores de Ehrlich em camundongos (ARAÚJO et al., 2010), e em estudos sobre seu vasto potencial polinizador, indicando que esta é uma espécie excepcional na coleta de compostos químicos da natureza, fato esse que também é importante para a manutenção da biodiversidade nos ecossistemas (SOUZA et al., 2015), o extrato da própolis da referida abelha não apresentou resultados satisfatórios na presente pesquisa frente aos grupos microbianos testados.

Tais resultados evidenciam a necessidade de mais pesquisas que contemplem novas formas de obtenção do extrato, outros mecanismos de proliferação microbiana e demais cepas, tanto in vitro como in vivo, a fim de se obter dados mais precisos que fomentem ou descartem a utilização de tal composto pela indústria farmacêutica e demais aplicabilidades.

\section{REFERÊNCIAS}

ARAÚJO, M. J. A. M.; DUTRA, R. P.; COSTA, G. C.; REIS, A. S., ASSUNÇÃO, A. K. M.; LIBÉRIO, S. A.; MACIEL, M. C. G.; SILVA, L. A.; GUERRA, R. N. M.; RIBEIRO, M. N. S.; NASCIMENTO, F. R. F.. Efeito do tratamento com própolis de Scaptotrigona aff. Postica sobre o desenvolvimento do tumor de Ehrlich em camundongos. Revista Brasileira de Farmacognosia, Curitiba, v.20, n.4, 2010. DOI: http://doi.org/10.1590/S0102-695X2010000400018

BANKOVA, V.; MARCUCCI, M. C.; SIMOVA, S.; NIKOLOVA, N.; KUJUMGIEV, A.; POPOV, S.. Antibacterial diterpenic acids from Brazilian propolis. Verlag der Zeitschrift für Naturforschung, v.51c, p.277-280, 1996. DOI: http://doi.org.10,1515/znc-1996-5-602

BURDOCK, G. A.. Review of the biological properties and toxicity of the bee propolis. Food and Chemical Toxicology, Tallahassee, v.36, p.347-363, 1998. DOI: http://doi.org/10.1016/s0278-6915(97)00145-2

CLSI. M 02-A12: Performance Standards for Antimicrobial Disk Suaceptibility Tests. 12 ed. Harrisburg: CLSI, 2015.

COSTA, A. S.; MACHADO, B. A. S.; UMSZA-GUEZ, M. A.; CIRQUEIRA, M. G.; NUNES, S. B.; PADILHA, F. F.. Levantamento dos estudos com a própolis produzida no estado da Bahia. Revista Sitientibus série Ciências Biológicas, Feira de Santana, v.18, n.13, p.1-7, 2014. DOI: http://doi.org/10.13102/scb324

ESTRELA, C.; ESTRELA, C. R. A.; BAMMANN, L. L.; PECORA, J. D.. Two methods to evaluate the antimicrobial action of calcium hydroxide paste. Journal of Endodontics, v.27, n.12, p.720-723, 2001. DOI: http://doi.org/10.1097/00004770200112000-00002

FERRONATTO, R.; MARCHESAN, E. D.; PEZENTI, E.; BEDNARSKI, F.; ONOFRE, S. B.. Atividade antimicrobiana de óleos essenciais produzidos por Baccharis dracunlifolia D. C. e Baccharis uncinella D. C. (Asteraceae). Revista Brasileira de Farmacognosia, João Pessoa, v.17, n.2, p.224-230, 2007. DOI: http://doi.org/10.1590/S0102-695X2007000200016

GHISALBERTI, E. L.. Propolis: A review. Bee World, Perth, v.60, n.2, p.59-84, 1979. DOI:

http://doi.org/10.1080/0005772X.1979.11097738

GOMES, B. P. F. A.; VIANNA, M. E.; SENA, N. T.; ZAIA, A. A.; FERRAZ, C. C. R.; SOUZA FILHO, F. J.. In vitro evaluation of the antimicrobial activity of calcium hydroxide combined with chlorhexidine gel used as intracanal medicament. Cirurgia Oral, Medicina Oral, Patologia Oral, Radiologia Oral e Endodontologia, v.102, n.4, p.544-550, 2006. DOI: http://doi.org/10.1016/i.tripleo.2006.04.010

LUSTOSA, S. R.. Padronização de extrato de própolis e avaliação da atividade antimicrobiana. Dissertação (Mestrado em Ciências Farmacêuticas) - Universidade Federal de Pernambuco, Recife, 2007.

MARCUCCI, M. C.. Propolis: chemical composition, biological properties and therapeutic activity. Apidologie, Berlin, v.26, n.2, p.83-99, 1995. DOI:

http://doi.org/10.1051/apido:19950202

MARCUCCI, M. C.. Propriedades biológicas e terapêuticas dos constituintes químicos da própolis. Química Nova, Campinas, v.19, n.5, p.529-535, 1996.

MIORIN, P. L.; LEVY JUNIOR, N. C.; CUSTODIO, A. R.; BRETZ, W. A.; MARCUCCI, M. A.. Antibacterial activity of honey and propolis from Apis melifera and Tetragonisca angustula against Staphylococcus aureus. Journal of Applied Microbiology, Campinas, v.95, p.913-920, 2003. DOI: http://doi.org/10.1046/j.1365-2672.2003.02050.x

PIANARO, A.. Ecologia química de Melipona quadrifasciata Lepeletier, Scaptotrigona aff. Depilis Moure e Solenopsis saevissima Smith. Tese (Doutorado em Química) Universidade Estadual de Campinas, São Paulo, 2012.

PINTO, L. M. A.; PRADO, N. R. T.; CARVALHO, L. B.. Propriedades, usos e aplicações da própolis. Revista Eletrônica de Farmácia, Lavras, v.8, n.3, p.76-100, 2011. DOI: http://doi.org/10.5216/ref.v8i3.15805

SOUZA, H. R.; CORRÊA, A. M. S.; CRUZ-BARROS, M. A. V.; ALBUQUERQUE, P. M. C.. Espectro polínico da própolis de 
Scaptotrigona aff. Postica (Hymenoptera, Apidae, Meliponini) em Barra do Corda, MA, Brasil. Acta Amazônica, v.45, n.3, p.307-316, 2015. DOI:

http://doi.org/10.1590/1809-4392201403663

TRINDADE, C. S. P. C.. Avaliação dos potenciais antioxidante e antimicrobiano da própolis das abelhas nativas Melipona quadrifasciata anthidioides, Plebeia droryana e
Scaptotrigona depilis (Hymenoptera, Apidae). Dissertação (Mestrado em Entomologia e Conservação da

Biodiversidade) - Universidade Federal da Grande Dourados, Dourados, 2012.

VILLAS-BÔAS, J.. Manual Tecnológico de Aproveitamento Integral dos Produtos das Abelhas Nativas Sem Ferrão. 2 ed. Brasília: ISPN, 2018

A CBPC - Companhia Brasileira de Produção Científica (CNPJ: 11.221.422/0001-03) detém os direitos materiais desta publicação. Os direitos referem-se à publicação do trabalho em qualquer parte do mundo, incluindo os direitos às renovações, expansões e disseminações da contribuição, bem como outros direitos subsidiários. Todos os trabalhos publicados eletronicamente poderão posteriormente ser publicados em coletâneas impressas sob coordenação da Sustenere Publishing, da Companhia Brasileira de Produção Científica e seus parceiros autorizados. Os (as) autores (as) preservam os direitos autorais, mas não têm permissão para a publicação da contribuição em outro meio, impresso ou digital, em português ou em tradução. 